\title{
VARIOUS CHALLENGING ASPECTS OF HYBRID PROPULSION
}

\section{O. Orlandi, D. Theil, J. Saramago, P. G. Amand, F. Dauch, and P. Gautier}

SNPE Matériaux Energétiques France

The hybrid technology appears as an innovative, high performance, and promising propulsion technique in a number of space missions. By combining functions and advantages taken from both solid and liquid propulsion, this technology is expected to provide mainly high performance with throttleability and stop-restart capabilities. The safety conditions of engine operation and design reliability almost similar to solid propulsion increase the interest to this technology. However, the standard fuels (mainly based on a carbon polymer) exhibit low regression rates that require complex grain shapes and low loading ratio. Thanks to a dedicated study supported by the European Space Agency (ESA), SNPE in collaboration with Avio and University of Naples (DIAS department) performed an exhaustive state-of-the-art and a market survey of accomplishments in hybrid propulsion. Based on the resulting tradeoff study on potential future launchers and spacecraft applications, the most promising applications are selected to conduct preliminary designs. These applications can also be seen as the vector of hybrid propulsion development. This study concentrates on hybrid propulsion systems with advanced hybrid fuels for Lander platform and Upper Stage. High throttleability and high propulsive performance associated with stop and restart capability are needed to meet mission requirements for Lander and Upper Stage, respectively. Preliminary design shows the advantages provided by hybrid propulsion: a significant payload mass increase for the upper stage case and a soft landing for the Lander case.

\section{INTRODUCTION}

Hybrid propulsion appears to be very attractive for space applications. It can be considered as an interesting technology combining advantages of solid and liquid propulsion. A hybrid engine could offer high performance with high specific impulse by using metallic hydrides in Hydroxy-Terminated Polybutadiene (HTPB) binder, for instance, up to $360 \mathrm{~s}$ for $\mathrm{HTPB} / \mathrm{AlH}_{3} / \mathrm{N}_{2} \mathrm{O}_{4}$ or $380 \mathrm{~s}$ for $\mathrm{HTPB} / \mathrm{AlH}_{3} / \mathrm{LOx}$ at $7 \mathrm{MPa}$ and nozzle expansion ratio of 40 in vacuum. It

This is an Open Access article distributed under the terms of the Creative Commons Attribution-Noncommercial License 3.0, which permits unrestricted use, distribution, and reproduction in any noncommercial medium, provided the original work is properly cited. 
also provides operating functions such as throttleability, stop and restart capability, and increase in the safety by separating the oxidizer and fuel, etc. All these characteristics allow definition of new missions based on hybrid propulsion. Compared to a standard liquid system, it is characterized by a safer operation thanks to reducing the number of liquid propellants and design simplicity.

However, classical hybrid propulsion also presents some weaknesses which were the reasons of its limited development up to now: low regression rate of the fuel yielding the complex shape of grains (typically wagon wheel grains), a low volumetric loading ratio, formation of residuals (to be considered as inert mass), and performance modulation by the evolution of oxidizer-to-fuel $(\mathrm{O} / \mathrm{F})$ ratio.

In order to overcome these weaknesses, many studies at laboratory scale have been carried out on hybrids over the last years. In particular, SNPE is conducting in cooperation within eight partners (Astrium SAS and Astrium GmbH, Avio, Onéra, DLR, Politecnico di Milano, University of Naples, University Polytechnic of Bucharest, Thyia) the Operative Research Project on Hybrid Engine in Europe (ORPHEE), funded by the European Commission's Seventh Framework Programme (FP7/2007-2013). The overall logic of this project is to increase the advanced fuel Technological Readiness Level (TRL) from a value of 1 to 3 and to propose a coherent approach dealing with the identification of promising applications, mathematical modeling design of demonstrators and test bench, and edification of technological roadmap. Nevertheless, in 2004, the success of two flights of Space Ship One, that won the Ansari X prize, definitely presented hybrid technology as a very promising propulsion concept and demonstrated the validity of this concept which historically began in the 1930s.

Finally, US experience in large hybrid motors (in-flight-proven or demonstrators such as Hysperion I \& II, SpaceShipOne, etc.) seems to be weakly balanced in Europe.

\section{FOCUS ON BURNING RATE INCREASE}

The increase of the regression rate is a real challenge for new advanced fuel formulations and development of hybrid technology. Indeed, the use of standard HTPB based fuel leads to complex grain shapes for which the burning surface is optimized in order to ensure the required mass flow rate (regression rate roughly of the order of $1 \mathrm{~mm} / \mathrm{s}$ ). Such an approach has been largely illustrated during US research programs in the 1980s (American Rocket Company (AMROC), Hybrid Technology Options Project (HyTOP), or Hybrid Propulsion Demonstration Program (HPDP)). The solution consists in multiplying the number of grain ports leading to wagon wheel configurations shown in Fig. 1. However, enhancement of the regression rate of standard fuel can be achieved by several ways mainly based on an increased heat transfer from the flame to the grain surface. As a matter of fact, 


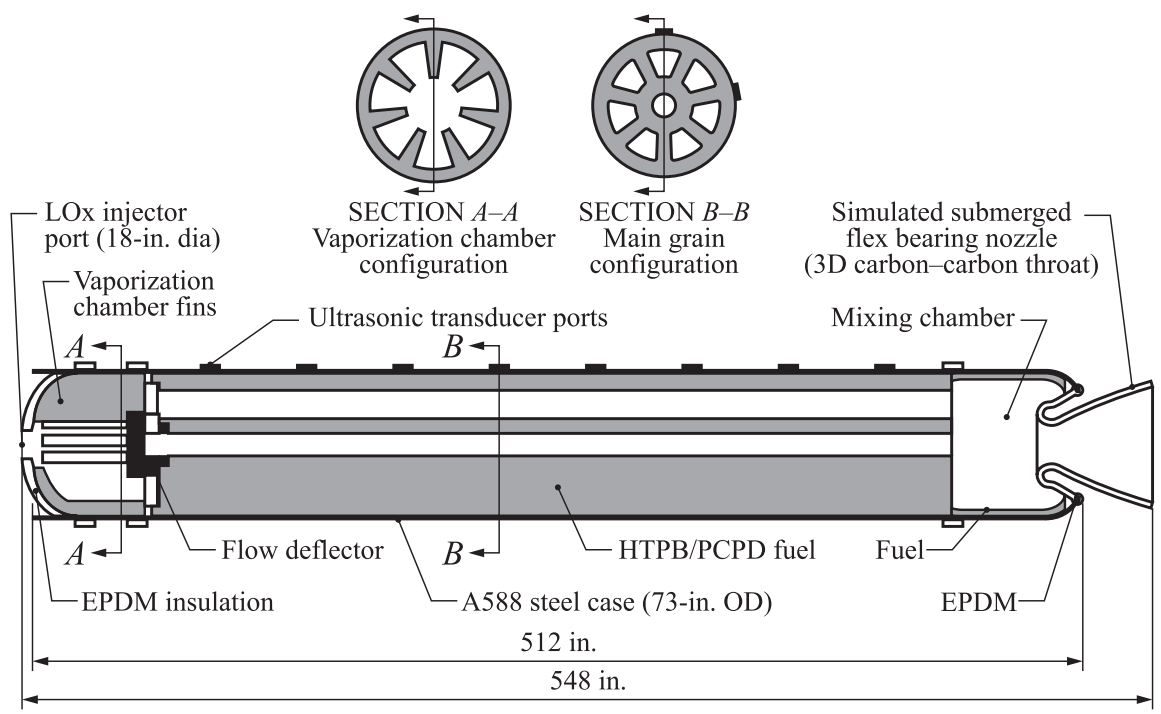

Figure 1 Example of complex engine geometry caused by low fuel regression rate (from HPDP program [1])

- introduction of solid oxidizer loads (Ammonium Perchlorate (AP) particles) in the grain promotes the combustion in a very thin reactive layer close to the surface;

- addition of metallic particles such as nanosized aluminum particles can increase the regression rate by a factor of 2 by augmenting heat feedback to the regressing surface. However, for micrometric sizes, the gain is negligible [2];

- enhancement of turbulence promotes the oxidizer and fuel mixing;

- addition of metallic hydrides results in the release of hydrogen. Preliminary tests demonstrated the benefits of aluminum hydride: a regression rate increased by a factor $2-3$ with a small amount of powder $(11.5 \%$ of the fuel mass) [3]; and

- replacement of polymer-based fuel by low melting-temperature material such as paraffin $[4,5]$ transforms the combustion mechanism to be controlled by the atomization of the liquefied layer and the burning of droplets in the combustion chamber. However, paraffin suffers low mechanical properties which limits its use for large-scale hybrid engines.

In order to access a fuel with the regression rate much higher than pure HTPB (a targeted value of $5 \mathrm{~mm} / \mathrm{s}$ appears to be sufficient for most of the ap- 
plications, cf. next illustrative applications section), the European Commission funded the cooperative project ORPHEE, led by SNPE with the aim to make the undisputable benefits of hybrid technology available for industrial purposes, in particular, by obtaining a better maturity level on solid fuel. Therefore, the ORPHEE partners will jointly develop, test, and evaluate a new solid fuel formulation to demonstrate the ability of hybrid technology in space transportation applications. This technological breakthrough is envisaged by demonstrating that a significant increase of the solid fuel regression rate allows new grain design and performance increase for a given volume with reduction of manufacturing costs.

The overall study logic is based on the achievement of demonstrators' designs and associated test bench and diagnostic needs. The achievement of such a goal implies mastering fuel regression as well as in oxidizer injection and the general operating process of a hybrid motor. The design of hybrid propulsion system requires clear definitions of potential applications which will be achieved with regard to market analysis. However, the foreseen applications strongly depend on fuel and oxidizer combinations that appear to be a key issue for the technology development (combustion performance and stage design). On the solid fuel side, the implementation of suitable additives is crucial to improve the regression rate and propulsive performances.

Because a robust design must be based on the knowledge of physical phenomena, a large task is dedicated to modeling issues. The aim is to provide numerical models to simulate the operation of a hybrid engine. Due to the complexity of the operation process, this task will be mainly focused on the fundamental aspects: solid fuel mastering, oxidizer injection mastering, and influence of turbulence on the performance. The modeling aspects will be sustained by experimental results obtained at small-scale combustion characterization level and subscale motor configuration. Finally, performance models will be implemented in the demonstrators' designs for two selected applications referring to launcher stage and Lander. On the road to a full-scale engine, subscale experiments and advanced diagnostics means are of crucial importance to measure and visualize the performance and burn-out characteristics of hybrid propulsion systems over time. To achieve that goal, assessment of the available test benches in Europe and capabilities of building such demonstrators will be performed and a technological road map aimed at increasing the TRL status of hybrid propulsion from 1 to 3-4 will be elaborated.

\section{PRELIMINARY DESIGNS OF HYBRID ENGINES}

Some of the following results are a part of the study performed within the frame of a Technological Research Program "Hybrid propulsion evaluation for liquid 
booster application" funded by ESA. They present illustrative aspects of benefits provided by hybrid propulsion in the cases of upper stage and Lander applications.

\section{Performance Assessments}

The composition of solid fuel is a crucial issue for hybrid propulsion technology. Related to solid propellant developments, many studies deal with standard binders such as HTPB that is generally considered as a baseline in terms of propulsive performance and regression rate (especially since the Space Ship One success). Most of the studied fuels applied to hybrid propulsion consider a nonpyrotechnic classification taking full benefit of safety issues. Figure 2 shows the specific impulse as a function of $\mathrm{O} / \mathrm{F}$ ratio. These results are obtained with the SNPE code OPHELIE based on the thermochemical shifting equilibrium assumption. For all tested fuels, the oxidizer is LOx. A combustion pressure of $7 \mathrm{MPa}$ and a nozzle expansion ratio of 40 are considered. As it can be seen, most polymers present similar performances (thermosetting polymers such as HTPB, Carbo-Terminated Poly Butadiene (CTPB), Poly Butadiene Acrylonitrile (PBAN), or thermoplastic as Poly-Ethylene (PE), Poly-Urethane (PU), or Di-Cyclo Pentadiene (DCPD)). In the same way, paraffin provides the same specific impulse evolution. These entire pure fuels exhibit an optimum value larger than $350 \mathrm{~s}$ for an $\mathrm{O} / \mathrm{F}$ ratio in the range of $2-3$. The maximum reached specific impulse (theoretical) is comparable to the performance of standard bi-liquid propellants $\left(I_{\mathrm{S}} \sim 360 \mathrm{~s}\right)$. Polymethyl Methacrylate (PMM), PU, Polybutadiene Latex (PBL), and Polyvinyl Choride (PVC) appear to be less interesting in terms of performance.

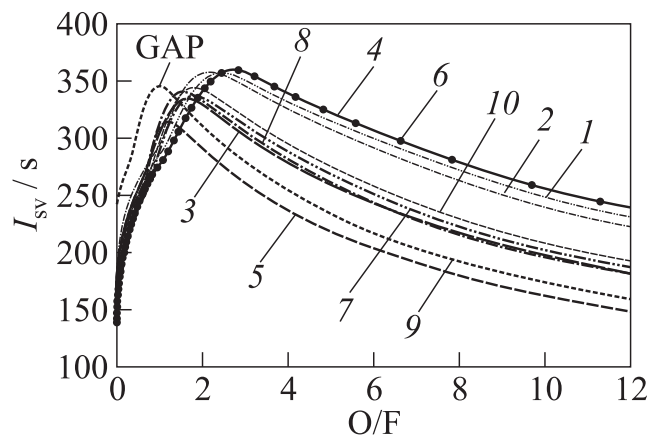

Figure 2 Theoretical specific impulse in vacuum obtained for different fuel/LOx couples $(P=7 \mathrm{MPa}, \Sigma=40): 1-\mathrm{HTPB} ; 2-\mathrm{CTPB} ; 3-\mathrm{PE} ; 4-\mathrm{PMM} ; 5-$ PVC; 6 - paraffin; 7 - PBL; 8 - Polyethylene glycol (PEG); 9 - Poly Alkylene Glycol (PAG); and $10-\mathrm{PU}$ 


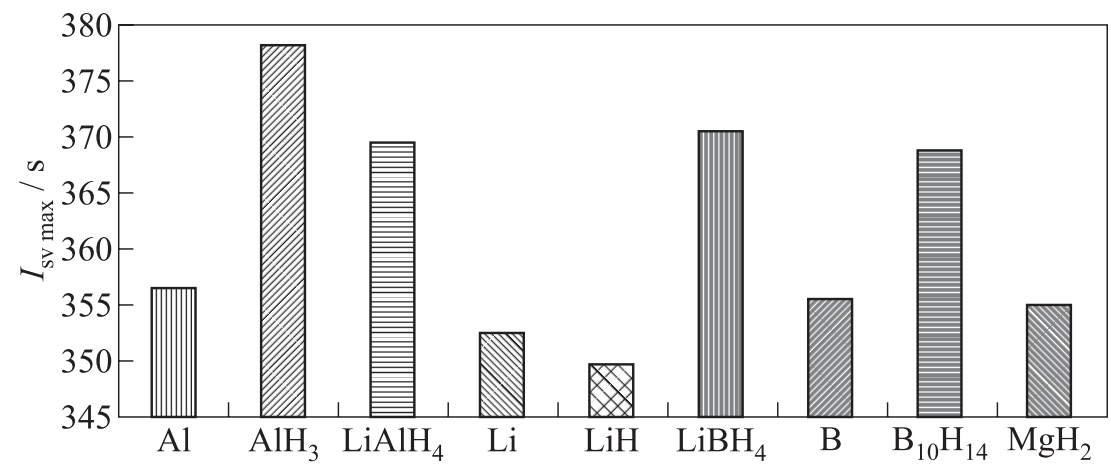

Figure 3 Theoretical specific impulse in vacuum for different additives to fuel/LOx couples [2]

For the purposes of comparison, the corresponding performance of Polyglycidyl Azide (PAG) is added to Fig. 2. The maximum $I_{\mathrm{S}}$ is close to those of butadiene-based polymers with an interesting optimum $\mathrm{O} / \mathrm{F}$ ratio close to one. However, this fuel exhibits a specific self-burning behavior and its main feature is unusual regression rate which can be regarded as a drawback for stop and restart functions. This difficulty can be overcome by mixing a pure fuel such as HTPB with PAG. Unfortunately, the high regression rate is dramatically affected by this mixing.

For increasing the propulsive performance, combustion of metals appears to be a promising alternative. Based on solid propellant background, the selected metals or hydrides are presented in Fig. 3 which summarizes the maximum theoretical specific impulse obtained with HTPB. As is seen from Fig. 3, $\mathrm{AlH}_{3}$ provides a significant increase of the optimal specific impulse. Other hydrides such as $\mathrm{LiAlH}_{4}, \mathrm{LiBH}_{4}$, or $\mathrm{B}_{10} \mathrm{H}_{14}$ roughly add $10 \mathrm{~s}$ to the specific impulse. It must be noted that aluminum does not increase $I_{\mathrm{s}}$. However, its addition can be of interest due to increasing the fuel volumetric weight and shifting the optimum $\mathrm{O} / \mathrm{F}$ ratio closer to 1 .

The oxidizer selection is based on the following main parameters depending on the mission requirements: performance, thrust modulation, reignition capability, storability and lifetime, safety, toxicity (i. e., oxidizers such fluorine are generally disregarded), or risks mastering. Based on the large variety of liquid and cryogenic propulsion concepts, the following oxidizers have been examined:

- LOx, the most energetic oxidizer, not as toxic as fluorine or $\mathrm{ClF}_{3}$. Its applications are Earth-To-Orbit (ETO) missions. Due to low boiling temperature $(90.18 \mathrm{~K})$, it is not well fitted for long-term storage missions (typically, planet exploration; perhaps, possibility for Moon Lander with special 
storage design). It is widely used and provides excellent performance, and its handling is mastered;

- MON (Mixed Oxides of Nitrogen) $\left(\mathrm{N}_{2} \mathrm{O}_{4}+\mathrm{NO}\right.$ addition for stability purpose), offers storage capability, many its components are off the shelf. It is characterized by good performance, exhibits some toxicity, but its handling is also mastered;

- $\mathrm{N}_{2} \mathrm{O}$ (Nitrous Oxide), generally considered as a safe oxidizer despite the explosion occurred during Space Ship One program [6]. It is mainly used for specific applications such as manned suborbital flight for which performance is not of primary importance. It presents a good storage capability with autopressurization limited to low pressures (5.85 $\mathrm{MPa})$;

- IRFNA (Inhibited Red Fuming Nitric Acid), contains more than $86 \%$ of nitric acid; it is no longer used and is replaced by MON. As a toxic compound, its handling is mastered;

- $\mathrm{H}_{2} \mathrm{O}_{2}$ presents potentially good propulsive performances; however, the addition of some quantity of water $(10 \%-15 \%)$ limits the maximum vacuum specific impulse to $\sim 311 \mathrm{~s}$. Difficulties in long-term conservation of hydrogen peroxide have been reported. These difficulties are mainly due to the incompatibility with tank materials and to the possibility of autocatalytic decomposition. Risks can be mastered when using high grades up to $95 \%-$ $98 \%$; but this approach involves difficulties dealing with the production of such high grades; and

- HAN (Hydroxyl Ammonium Nitrate), has recently emerged as a potential ingredient for propulsion, both as a monopropellant (considered as a potential candidate for the replacement of hydrazine) and as an oxidizer. The solutions are actually mixtures of HAN and ammonium nitrate $(\mathrm{AN})$. HAN is incompatible with some materials, such as transition metals. Therefore, precaution should be taken for its storage although addition of small amounts of a stabilizing agent could strongly reduce the risk of decomposition. HAN is nontoxic. Gelled form can be achieved by using inorganic gelling like $\mathrm{SiO}_{2}$ as well as hydrosoluble polymers.

Figure 4 presents theoretical dependences of the specific impulse vs. O/F for different oxidizer/HTPB couples. The sharp shape of the optimum can be observed. This parameter allows considering the oxidizer modulation (mass flow rate variation) without significant loss of performance in the case of a flat maximum.

Table 1 extracted from Fig. 4 shows the characteristics of optimum $I_{\mathrm{sv}}$ for different oxidizers. As can be seen, the most promising oxidizer is LOx if nonstorable specification is applicable. In case on long-term storability, MON seems to be a good candidate as well as hydrogen peroxide. Moreover, the selection of 


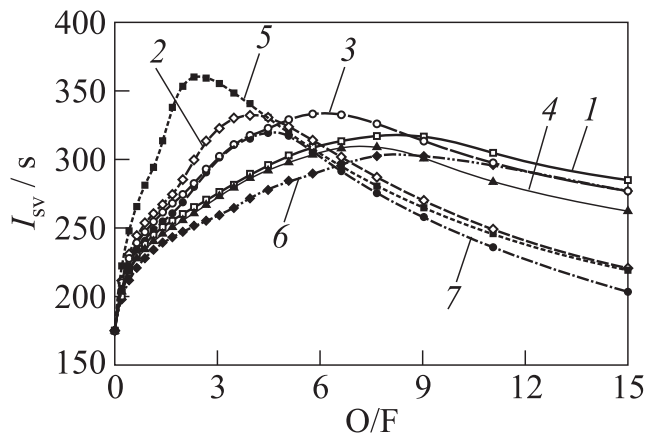

Figure 4 Theoretical specific impulse for different oxidizer/HTPB couples $(P$ $=7 \mathrm{MPa}, \Sigma=50): 1-\mathrm{N}_{2} \mathrm{O} ; 2-\mathrm{N}_{2} \mathrm{O}_{4} ; 3-\mathrm{H}_{2} \mathrm{O}_{2}(100 \%) ; 4-\mathrm{H}_{2} \mathrm{O}_{2} / \mathrm{H}_{2} \mathrm{O}$ $(85 \% / 15 \%) ; 5-\mathrm{LOx} ; 6-\mathrm{HAN}$; and 7 - IRFNA

Table 1 Theoretical specific impulse (max) computed for different oxidizers with HTPB

\begin{tabular}{lcc}
\hline \multicolumn{1}{c}{ Oxidizer } & $I_{\mathrm{sv}}^{*}, \mathrm{~s}$ & $\mathrm{O} / \mathrm{F}\left(\max I_{\mathrm{sv}}\right)$ \\
\hline $\mathrm{LOx}$ & 361 & 2.75 \\
$\mathrm{~N}_{2} \mathrm{O}$ & 317 & 8 \\
$\mathrm{MON}\left(\mathrm{N}_{2} \mathrm{O}_{4}+\mathrm{NO}\right)$ & 334 & 4 \\
$\mathrm{IRFNA}$ & $\sim 312$ & $\sim 4$ \\
$\mathrm{H}_{2} \mathrm{O}_{2}$ & $334^{* *}$ & 5.7 \\
$\mathrm{HAN}$ & 303 & 9 \\
\hline${ }^{*} I_{\mathrm{sv}}$ obtained for pressure of $7 \mathrm{MPa}$ and expansion \\
ratio of 50. \\
${ }^{* *}$ For pure $\mathrm{H}_{2} \mathrm{O}_{2}$.
\end{tabular}

the fuel should take into account the $\mathrm{O} / \mathrm{F}$ ratio and take advantage of the lowest values (this selection will be performed with regard to the required mass flow rate and turbopump capability).

\section{PROMISING APPLICATIONS}

Based on a market survey, two promising applications have been selected [7]. The corresponding rating was applied considering the high level requirements linked with hybrid propulsion advantages.

\subsection{Upper Stage}

The Upper Stage application is based on the replacement of the Vega launcher Z9 and aviation unit maintenance (AVUM) engines by a unique stage based on 
hybrid technology. The selected mission is a 700-kilometer circular orbit with a 90 degree inclination. The study aims to evaluate the potential increase of payload mass taking full advantage of a hybrid engine compared to a reference system. To achieve such a goal, the first and second stages are kept as in their reference design. An optimization procedure is then applied to the payload mass in order to reach the targeted orbit.

The proposed engine is then based on the requirements of the Z9 \& AVUM stages and on the following tasks:

- selection among the AVUM equipment those units that will be integrated to the equipment sector of the stage under study;

- selection of the diameter to be adapted to the existing structures; and

- selection of the same propellant mass as for the existing platform (Z9 \& AVUM).

The studied case considered an advanced HTPB-based fuel loaded with aluminum hydrides (66\%(mass.)). For LOx, the maximum specific impulse $(380 \mathrm{~s}$ is vacuum) in obtained for the $\mathrm{O} / \mathrm{F}$ ratio of one. This leads to the same mass of the fuel grain and liquid oxidizer. As regression rate remains a real issue for such an amount, the law used for this calculation is extrapolated from the results obtained in $[2,3]$ and the assumption was made that $r_{b}=0.57 \mathrm{GOx}^{0.6}$ where $r_{b}$ is taken in $\mathrm{mm} / \mathrm{s}$ and GOx in $\mathrm{kg} /\left(\mathrm{m}^{2} \cdot \mathrm{s}\right)$. No lower limit in the GOx parameter was applied (the minimum value of $10 \mathrm{~kg} /\left(\mathrm{m}^{2} \cdot \mathrm{s}\right)$ in the calculation; as GOx tends to zero, so does the regression rate). The geometry of the grain is kept as simple as possible: a cylindrical grain with a central bore is selected. As the outer diameter is a requirement, the only parameter is the web thickness. The length of the grain is then deduced from the overall mass needed. As the LOx mass flow rate is constant during engine operation, the regression rate decreases from $9 \mathrm{~mm} / \mathrm{s}$ at engine start to $2.3 \mathrm{~mm} / \mathrm{s}$ at the end of operation. The corresponding average regression rate is $3.6 \mathrm{~mm} / \mathrm{s}$. The calculation also shows that in this case, the variation of the $\mathrm{O} / \mathrm{F}$ ratio remains very limited ( 0.85 to 1.08 ) with a mean value of 1 . The resulting thrust level is nearly $200 \mathrm{kN}$ for a maximum value of $245 \mathrm{kN}$. The nozzle throat is designed to obtain an average pressure of 4.7 MPa.

The associated inert mass of the engine is composed of the mass of the composite combustion chamber including thermal insulation, ignition system, aluminum oxidizer tank, pressurization device, nozzle, and turbopump.

Two approaches for orbit injection are studied: a direct injection or an intermediate ballistic phase. The ballistic phase has a deep impact on the resulting trajectory and on the choice of the hybrid system technology. In this case, it has to resist to a long ballistic time with thermal evolution of the heated parts and thermal soak-back loads. For the purposes of comparison, the direct orbit trajectory is examined and presented in Table 2 even if a more developed interest 
Table 2 Hybrid Upper Stage characteristics (preliminary designs)

\begin{tabular}{lcccc}
\hline Characteristic & Unit & $\begin{array}{c}\text { VEGA } \\
\text { reference } \\
\text { Z9 \& AVUM }\end{array}$ & $\begin{array}{c}\text { Hybrid with } \\
\text { direct orbit } \\
\text { injection }\end{array}$ & $\begin{array}{c}\text { Hybrid with } \\
\text { ballistic } \\
\text { phase }\end{array}$ \\
\hline Diameter & $(\mathrm{m})$ & 1.9 & 1.9 & 1.9 \\
Length & $(\mathrm{m})$ & 3.9 & 6.4 & 6.4 \\
Initial mass & $(\mathrm{kg})$ & 138350 & 137750 & 138680 \\
Gross mass-Dry mass & $(\mathrm{kg})$ & $12716-2250$ & $11260-1260$ & $11350-1350$ \\
\hline Propellant & & & & \\
$\quad$ Solid & $(\mathrm{kg})$ & 9935 & 5000 & 5000 \\
$\quad$ LPS/LOx & $(\mathrm{kg})$ & 550 & 5000 & 5000 \\
\hline Average O/F ratio & & & 1 & 1 \\
Average $I_{\mathrm{sv}}$ & $(\mathrm{s})$ & $295 / 315$ & 360 & 360 \\
Maximum acceleration & $\left(\mathrm{m} / \mathrm{s}^{2}\right)$ & 41.2 & 40.3 & 44.7 \\
Burn time & $(\mathrm{s})$ & 772.4 & 500 & 180 \\
Payload mass & $(\mathrm{kg})$ & 1340 & 2150 & 2990 \\
\hline
\end{tabular}

demonstration of this solution would require a more precise study. Nevertheless, this procedure appears less constraining in terms of propulsion system despite its presumed low performances.

From a preliminary mission analysis, it appears [7] that the introduction of an intermediate ballistic phase is very sensitive on the payload performance $(\sim 800 \mathrm{~kg}$ gain) but it needs the control of a relatively short second boost (7 s) and control of heated parts. For both configurations (with and without

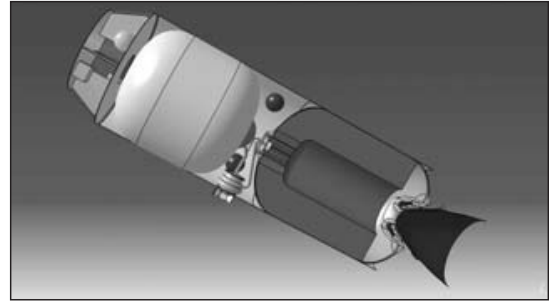

Figure 5 View of Hybrid Upper Stage Engine ballistic phase), the overall propellant mass remains the same. These results are complementary to those of [8] and illustrate the potential payload mass gain when using an advanced fuel (see Table 2).

To summarize, the total mass of the propellants is chosen to be $10,000 \mathrm{~kg}$ roughly corresponding to $10,000 \mathrm{~kg}$ of the Z9 solid propellant and $550 \mathrm{~kg}$ of liquid propellant of the AVUM. The proposed concept exhibits the potential of hybrid propulsion in terms of significant increase in the overall payload mass. Figure 5 shows the view of the engine. Some improvements can be considered since the intrinsic derivatives are positive $(0.15 \mathrm{~kg} / \mathrm{kg}$ or $150 \mathrm{~kg}$ of payload per ton of propellant). This mass could be optimized in further studies. 


\subsection{Mars Lander}

The approach adopted for the Mars Lander differs from that for the Upper Stage Engine because of the lack of reference for comparing the preliminary design. So, the study aims to propose a design of a hybrid engine that meets the requirements without any optimization on mass that lands.

To achieve such a goal, thrust modulation due to variation of the oxidizer injection appears as a real asset of hybrid propulsion. As a result of that capability, future exploration missions can envisage a soft landing scenario (i.e., no airbag use). For Mars Exploration Rover (MER) mission, the initial retro-rocket braking was followed by the release of the charge. The final touch down was insured by airbags deployment and went on with a bouncing phase.

Landing of a 1-ton mass on Mars is considered. In that context (Mars environment with a $3.74 \mathrm{~m} / \mathrm{s}^{2}$ gravity), the retro-rockets have to provide an approximate value of $\Delta V \sim 70 \mathrm{~m} / \mathrm{s}$. The retro-rocket operating follows a standard aerodynamics braking phase using parachutes. The thrust braking cannot be ensured by a single engine (the center location is dedicated to the rover) and a three-motor configuration is considered, all of them placed around the central body at $120^{\circ}$ angles. After the first braking phase, the second retro-rocket phase is considered for balancing the overall weight of the landing system allowing soft landing by tuning the thrust.

Figure 6 shows the evolution of the thrust (assuming that a single engine brakes $1 / 3$ of the overall mass, i.e., $333 \mathrm{~kg}$ ). The minimum is obtained by considering the total impulse of $50 \mathrm{kN} \cdot \mathrm{s}$ being delivered during $30 \mathrm{~s}$ for a weight of $1245.4 \mathrm{~N}$ which corresponds to the thrust of the hovering phase (not considered hereafter). The landing procedure is to start the retro-rocket braking phase with a high thrust level and to finish with a low thrust level that compensates the weight of the Lander (stationary flight) as shown in Fig. 6. This is achieved due

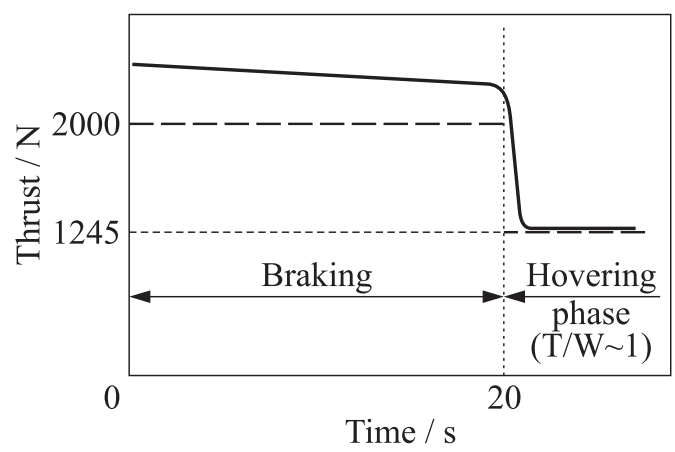

Figure 6 Example of mission profile 

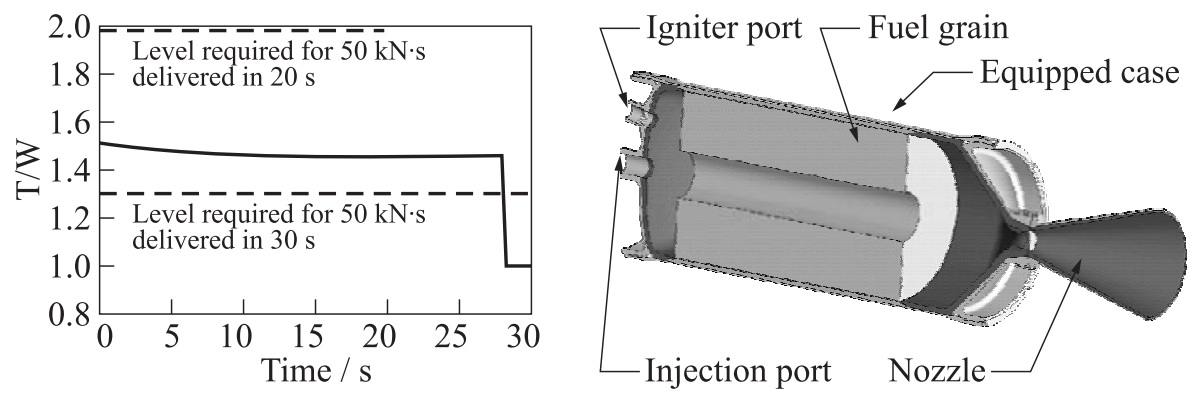

Figure 7 The time history of thrust-to-weight ratio and the engine computer aided design (CAD)

to the modulation capability of the hybrid motor and a well fitted initial design of the thrust law shape vs. time (for a given oxidizer depletion).

The overall retro-rocket architecture is then composed of three hybrid engines located in the descent module consisting of a combustion chamber with fuel grain $\left(\mathrm{HTPB} / \mathrm{AlH}_{3}\right)$, nozzle, single oxidizer tank with $\mathrm{N}_{2} \mathrm{O}_{4}$, and its injection devices (piping, pyrotechnic valves). A single pressurization device (Helium) is used to ensure the required pressure for the $\mathrm{N}_{2} \mathrm{O}_{4}$ tank.

The proposed design is based on the following assumptions: the oxidizer mass flow rate is constant, the mean $\mathrm{O} / \mathrm{F}$ ratio during the braking phase is optimal. The second assumption means that there would be no residuals (neither for the fuel grain nor for the oxidizer). This last hypothesis will have to be experimentally confirmed as well as the regression rate for the selected composition.

Figure 7 demonstrates that the modulation ratio should be of the order of $60 \%$ to obtain the thrust balancing the landing system weight.

In this preliminary design, a cylindrical shape is considered for combustion yield purpose (no residuals, easier manufacturing, etc.). $\mathrm{HTPB} / \mathrm{AlH}_{3}$ has been selected as a fuel, mainly, for its propulsive performance, and well-known HTPB background in solid propulsion. The proposed fuel has the following characteristics:

- $66 \% \mathrm{AlH}_{3}$ and $34 \% \mathrm{HTPB}$ with a density of 1.195 ; and

- a regression rate spreading from 5 down to $1.2 \mathrm{~mm} / \mathrm{s}$. The corresponding law is $r_{b}=0.2 \mathrm{GOx}^{0.6}$ (factor of 5 is expected in comparison with pure $\mathrm{HTPB}$ ). This range is considered as a target requirement and needs to be demonstrated in further fundamental experiments. The same regression law is used for both $\mathrm{N}_{2} \mathrm{O}_{4}$ and $\mathrm{N}_{2} \mathrm{O}$ oxidizers.

The $\mathrm{N}_{2} \mathrm{O}_{4}$ oxidizer is stored in a liquid state in a tank and pressurized by a Helium pressurization system. For operation needs, the $\mathrm{N}_{2} \mathrm{O}_{4}$ mass flow rate is 
Table 3 Overall $\mathrm{N}_{2} \mathrm{O}_{4}$ Hybrid Propulsion Module mass budget

\begin{tabular}{lccc}
\hline & Mass, $\mathrm{kg}$ & Margin, $\mathrm{kg}$ & Total, $\mathrm{kg}$ \\
\hline Dry mass & 54.78 & 17.982 & 72.762 \\
Fuel grain $(\# 3)$ & 23.4 & 0.702 & 24.102 \\
$\mathrm{~N}_{2} \mathrm{O}_{4}$ & 41.3 & 3.304 & 44.604 \\
Helium & 1.3 & 0.104 & 1.404 \\
\hline TOTAL & $\mathbf{1 2 0 . 7 8}$ & $\mathbf{2 2 . 0 9 2}$ & 142.872 \\
\hline
\end{tabular}

$0.45 \mathrm{~kg} / \mathrm{s}$ per motor is required during 20-second operation time. Margins are considered by including the possibility to provide the engine minimum continuous firing time of $30 \mathrm{~s}$ (in order to compensate additional needs for the combustion chamber).

The preliminary mass budget (Table 3) can be compared with the one of a design based on a "pure" HTPB fuel grain (equivalent performances but without $\mathrm{AlH}_{3}$ ): about $175 \mathrm{~kg}$. Thus, mass saving of about $20 \%$ is obtained in this first approach when adding $\mathrm{AlH}_{3}$ in the fuel grain.

An alternative solution is examined by considering $\mathrm{N}_{2} \mathrm{O}$ instead of $\mathrm{N}_{2} \mathrm{O}_{4}$. The overall engine architecture is not affected by this modification. As the vapor pressure of $\mathrm{N}_{2} \mathrm{O}$ is nearly $5 \mathrm{MPa}$, some bubbles could appear between the combustion chamber and the proportional valve in case of modulation yielding a chamber pressure level lower than $5 \mathrm{MPa}$. The additional development of the valve should consider this effect to ensure the correct mass flow injection.

Slight modifications deal with the fuel composition $\left(83 \% \mathrm{AlH}_{3}\right.$ and $17 \%$ HTPB) and nozzle expansion ratio of 60 . The first design studies outline a needed regression rate range from 1.3 to $8 \mathrm{~mm} / \mathrm{s}$. An overall mass budget of $150 \mathrm{~kg}$ including margins is obtained for this solution. The large amount of $\mathrm{N}_{2} \mathrm{O}$ (50 kg vs. $17 \mathrm{~kg}$ of solid fuel) is due to a maximum specific impulse obtained for the $\mathrm{O} / \mathrm{F}$ ratio of 2.45 .

An important issue for both solutions is the modulation ratio required to adjust the thrust-to-weight ratio. For the operating time of about $25-30 \mathrm{~s}$, it is observed that a 50 percent decrease in the thrust is satisfactory. However, it has to be noted that the thrust was optimized during the braking phase only. Further dedicated studies need to be performed for the thrust evolution during the entire mission including the hovering phase.

\section{CONCLUDING REMARKS}

This study highlights the need in new fuel formulations allowing enhanced propulsive performance and regression rate. The TRL of the fuel part remains 
relatively low. It appears that the main $\mathrm{R} \& \mathrm{D}$ efforts have to support the development of a new advanced fuel. The ORPHEE project aims to tackle this challenge with providing a fuel characterized by a high specific impulse comparable to bi-liquid propellants as well as a high regression rate.

Thanks to the availability of such new fuels, full benefits of hybrid technology based on high specific impulse, stop and restart, and thrust modulation capability will provide substantial enhancement of hybrid engines. This will result in a significant increase of the payload mass for an upper stage application and soft landing for a space exploration mission.

\section{ACKNOWLEDGMENTS}

Part of this study was funded by the European Space Agency. The ORPHEE project is supported by funding from the European Commission's Seventh Framework Programme (FP7/2007-2013) under grant agreement No. 218830.

\section{REFERENCES}

1. Story, G. 2007. Large-scale hybrid motor testing. In: Fundamentals of hybrid rocket combustion and propulsion. Eds. M. J. Chiaverini and K. K. Kuo. Progress in astronautics and aeronautics ser. AIAA. 218:513-52.

2. Risha, G.A., B. J. Evans, and K.K. Kuo. 2007. Metals, energetic additives, and special binders used in solid fuels for hybrid rockets. In: Fundamentals of hybrid rocket combustion and propulsion. Eds. M. J. Chiaverini and K. K. Kuo. Progress in astronautics and aeronautics ser. AIAA. 218:413-56.

3. Calabro, M., L. T. DeLuca, L. Galfetti, H. Raina, and C. Perut. 2007. Advanced hybrid fuels. 58th Astronautical Congress (International) Proceedings. Bangalore, India. IAC-07-C4.2.09.

4. Karabeyoglu, A., G. Zilliac, B. J. Cantwell, S. DeZilwa, and P. Castellucci. 2004. Scale-up tests of high regression rate paraffin-based hybrid rocket fuels. J. Propul. Power 20(6):1037-45.

5. Pelletier, N., and Y. Maisonneuve, 2008. Paraffin-based hybrid fuels: Model of regression and experiments. 2nd Symposium (International) on Propulsion for Space Propulsion. Heraklion, Crete.

6. Karabeyoglu, A., J. Dyer, J. Stevens, and B. J. Cantwell. 2008. Modeling of $\mathrm{N}_{2} \mathrm{O}$ decomposition events. AIAA Paper No. 2008-4933.

7. Walloshek, T., R. De Amicis, F. Dauch, P. G. Amand, and O. Orlandi. 2008. Hybrid propulsion assessment for space applications (launchers and spacecrafts). 2nd Symposium (International) on Propulsion for Space Propulsion. Heraklion, Crete.

8. Casalino, L., and D. Pastrone. 2008. Optimal design of hybrid rocket motors for launchers upper stages. AIAA Paper No. 2008-4541. 